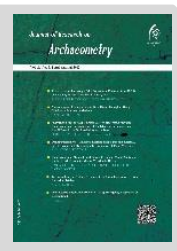

\title{
Identification of the Stain Structure Caused by Hand Contact on Historical Papers of the Pebdeni Museum of Old Manuscripts, Iran
}

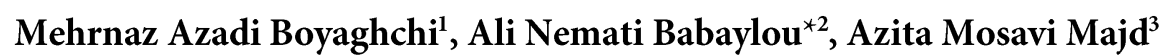 \\ ${ }^{1}$ Assistant Professor, Faculty of Conservation, Art University of Isfahan, Isfahan, IRAN \\ ${ }^{2}$ Assistant Professor, Faculty of Applied Arts, Tabriz Islamic Art University, Tabriz, IRAN \\ ${ }^{3} M . A$ in Conservation of Cultural Properties, Faculty of Conservation, Art University of Isfahan, Isfahan, \\ IRAN
}

Accepted: 23/12/2017

\begin{abstract}
The stains caused by hand contact on books are one of the problems in conservation of historical papers during the cleaning process. These stains are usually resistant and not easily soluble in solvents. Accordingly, it is necessary to know their structure in order to select the appropriate solvent and cleaning method. The aim of this article is to study the structure of stains caused by hand contact in historical papers. These stains are referred to as greasy stains in some texts, and many of them are old, and their abundance in some cases indicates the amount of object using. So, this article tries to answer the question of what is the chemical structure of the hand-caused stains on historical papers. For this purpose, Fourier Transform Infrared Spectroscopy (FTIR) was used to identify the structure of the stains in 20 samples of paper and paper works of Dariush Pebdeni collection in Foulad Shahr- Iran. Before the analysis, sizing material was identified by the classic methods and analysis carried out on the samples with the starch sizing. The results of this study showed that the structure of the stain is composed of sulfur proteins and does not have a fatty structure. The presence of absorption bands associated with $\mathrm{NH}$ and $\mathrm{CN}$ and the absence of carbonyl bands associated with carboxylic acids and esters shows that stains have proteinous structure and they are non-fatty stains. The absorption bands of the $700-900 \mathrm{~cm}^{-1}$ region can be attributed to out of plan bending $\mathrm{N}-\mathrm{H}$, which is combined in amide and amine samples. The strong bands at $1032 \mathrm{~cm}^{-1}$ and $1222 \mathrm{~cm}^{-1}$ can be due to C-N stretching in aliphatic amines. Also, skeletal vibrations of cycloalkanes can also produce a medium to strong adsorption band in the $1030 \mathrm{~cm}^{-1}$ region. The absorption band of the $1363 \mathrm{~cm}^{-1}$ in these samples is also due to $\mathrm{N}-\mathrm{O}$ nitro in amines and amides, and the absorption band of the $1114 \mathrm{~cm}^{-1}$ region is probably caused by C-O. Absorption bands related to $\mathrm{NH}$ and $\mathrm{CN}$, which is seen in the structure of amides and amines, and two specific absorption bands belonging to sulfur compounds $\left(470 \mathrm{~cm}^{-1}\right.$ resulting from S-S and $2518 \mathrm{~cm}^{-1}$ related to S-H) can indicate the protein's stains. Sulfuric amino acids in proteins include cysteine, cystine and methionine. The cysteine loses its hydrogen and, by forming a bond between the two sulfur atoms in the structure of the proteins, conjuncts the polypeptide chains. The presence of peptide bonds in the stain can be demonstrated by a C-N-C related absorption bands in the range of $1160 \mathrm{~cm}^{-1}$ and $1222 \mathrm{~cm}^{-1}$. Also it should be noted that the presence of adsorption bands related to $\mathrm{OH}$ stretching in $3440 \mathrm{~cm}^{-1}$ could indicate the oxidation of the product, which could justify the resistance of stains to conventional organic solvents. This absorption band that is
\end{abstract}

${ }^{*}$ Corresponding author: a.n.babaylou@tabriziau.ac.ir 
usually strong and broad, is observed in all samples and has overlapping with a stretching NH attraction of about $3300 \mathrm{~cm}^{-1}$. Accordingly, a comparative study of the Fourier Transformation Infrared Spectroscopy results of historical samples with animal proteins indicates the similarity of the spectrum of spots with the spectrum of animal glue and gelatin.

Keywords: Stain, Historical Paper, Pebdeni Collection, FTIR, Sulfur Proteins. 


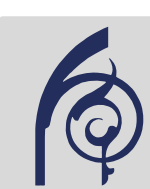

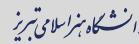

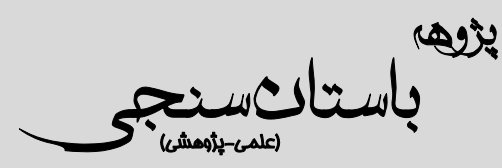

URL: http://jra-tabriziau.ir/

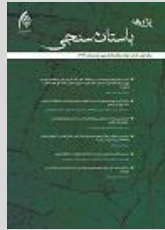

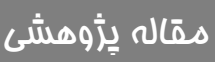

\section{شناسايـ ساختار گُركى ناشى از تماس دست در} كاغذهاى تاريخى موزه نسخ قديمى يبدنى

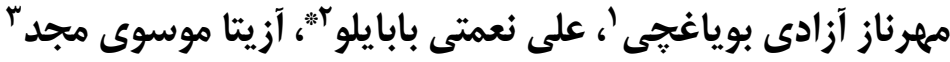

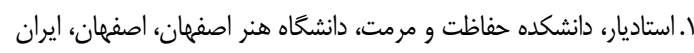

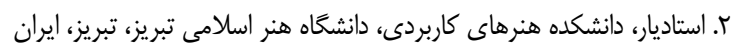

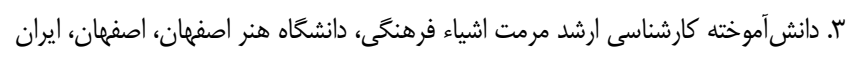

وجود لكه هاى ناشـى از تماس دست در اثر تورق كتب تاريخى يكى از مشكلات حفظ و مرمت كاغذهاى تاريخى طى فرايند تميزكارى

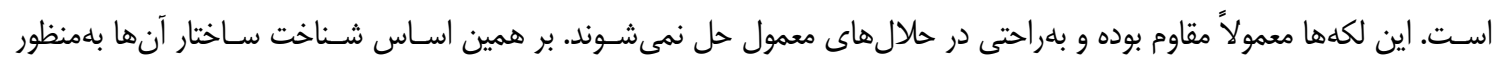

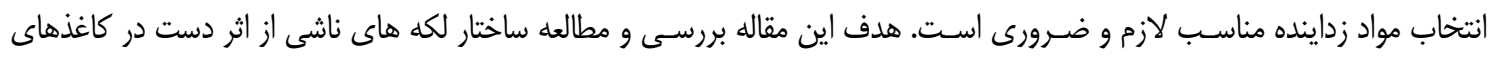

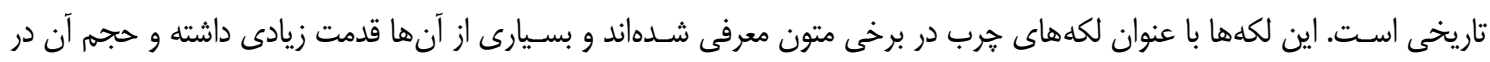

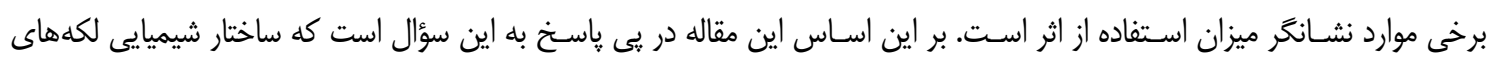

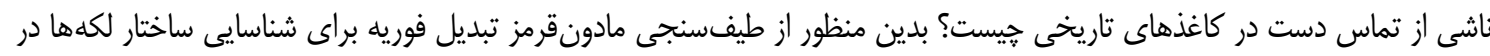

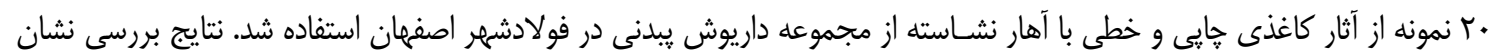

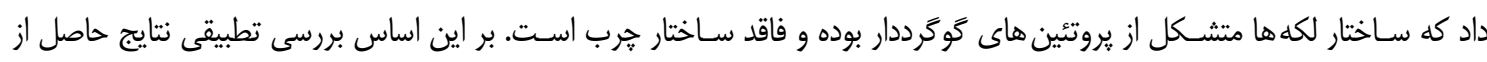

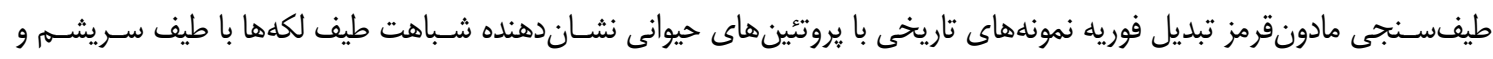
زلاتين است.

وازَّان كليدى: لكه، كاغذ تاريخى، مجموعه يبدنى، FTIR، يروتئين گوگرددار.

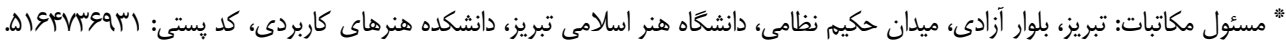

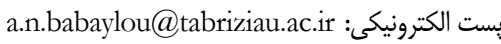

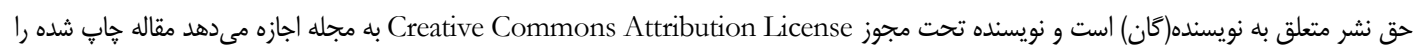


و قدرتى به بررسـى انواع لكه هاى موجود بر روى كاغذ،

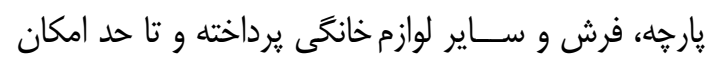

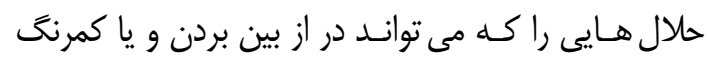

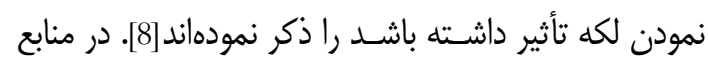

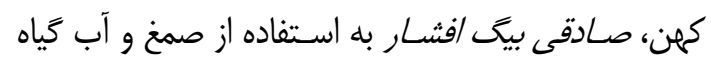

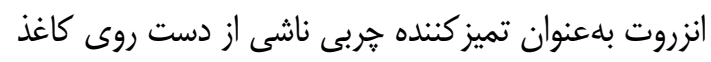

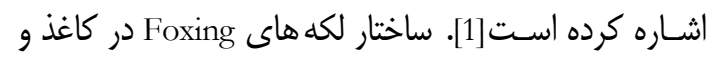

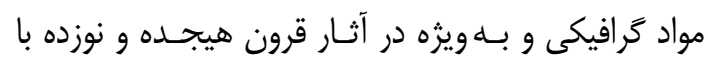

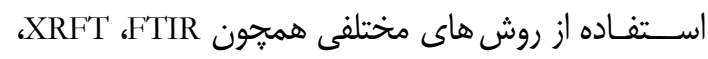

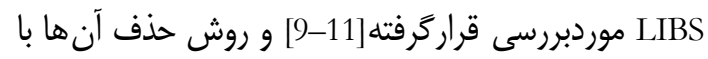

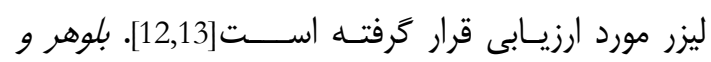

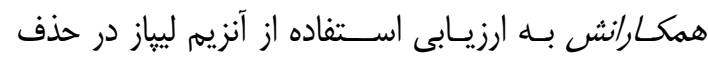

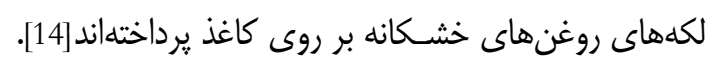

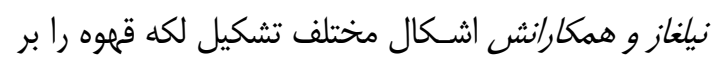

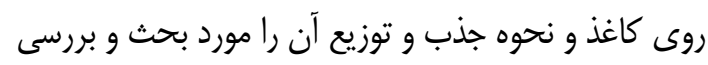

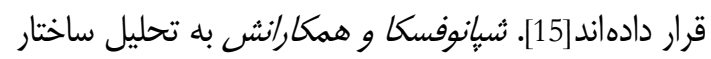

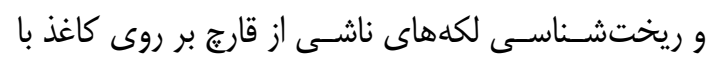

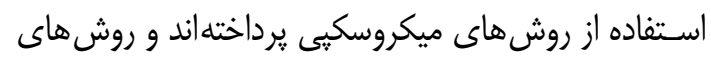

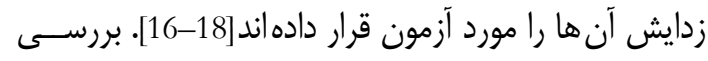

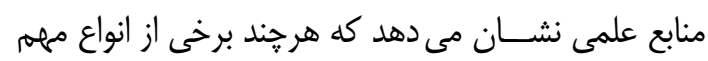

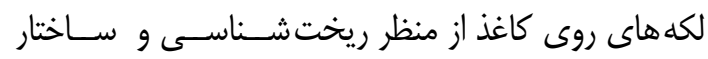

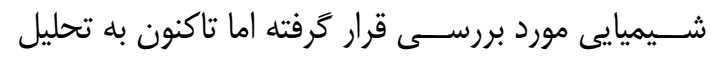
سـاختارى لكههاى ناشـى از تماس دست بلهعنوان يكى از

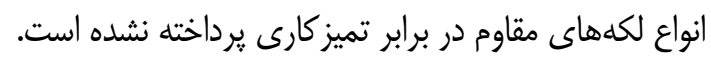

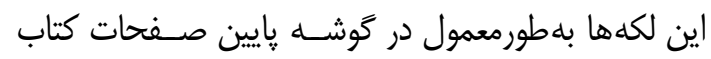

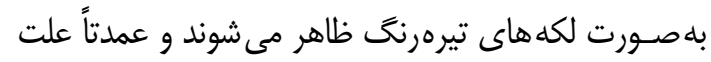

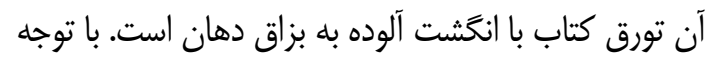

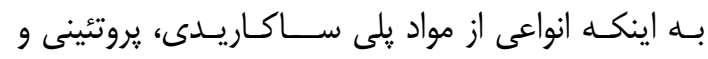

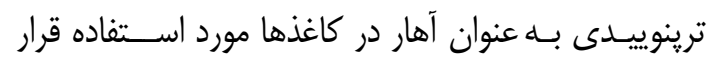

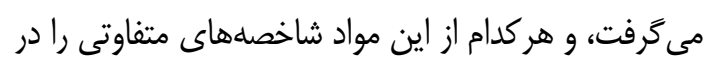

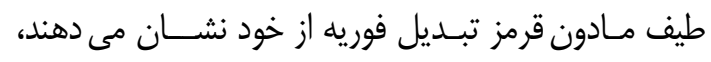

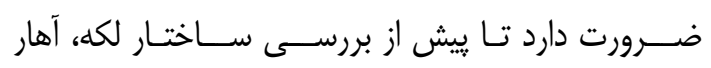
مورداستفاده در كاغذ شناسايى شود.

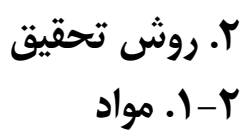

نمونه هاى تاريخى: براى شناسايى لكه، از لكه هاى ناشى

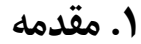

يكى از مشكلات حفظ و مرمت نسخ كهن، اعم از خطى و

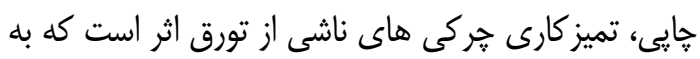

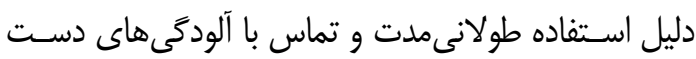

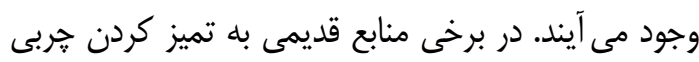

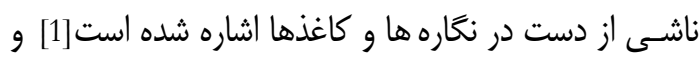

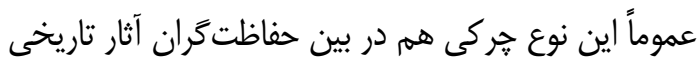

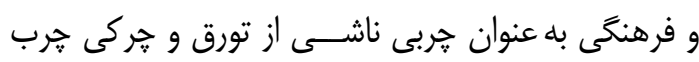

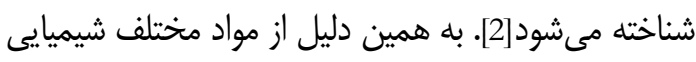

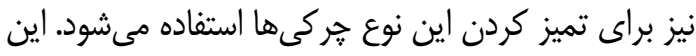

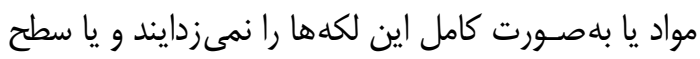
كاغذ را تخريب نموده و موجب خشكى و شكنندىى در آن آن مى شوند. همجنين برخى از اين مواد به دليل ميزان بالاى

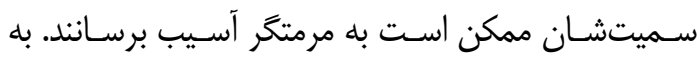

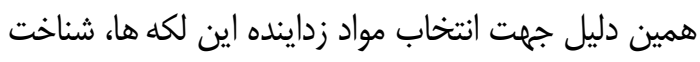

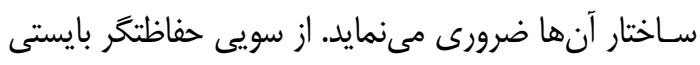

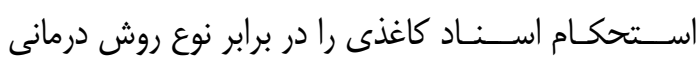

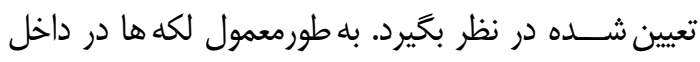

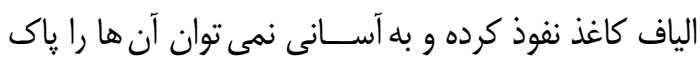

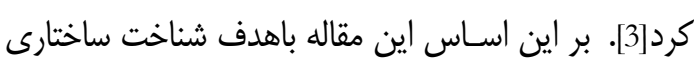

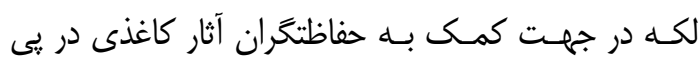
ياسـخكَويى بله اين سـؤال اسـت كه ساختار شيميايى لكه

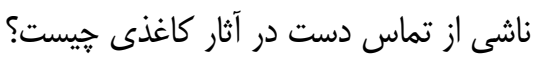

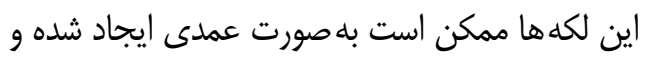

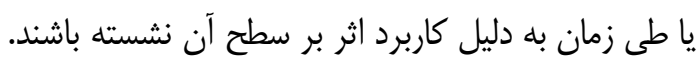

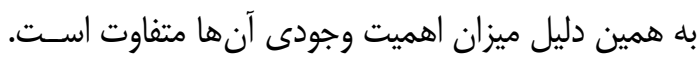
استكمن روش هاى شيميايى تميزكارى انواع لكه ها و مواد

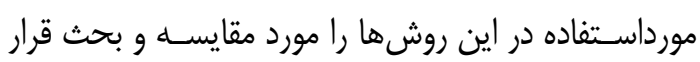
داده است[4]. - است

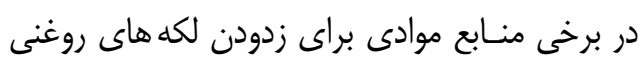

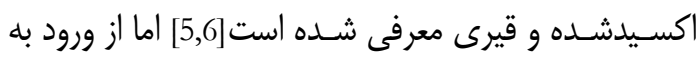

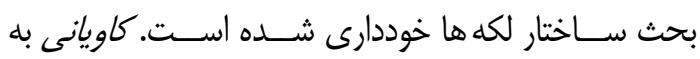

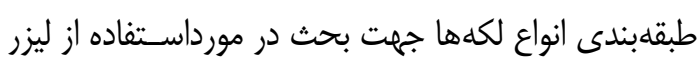

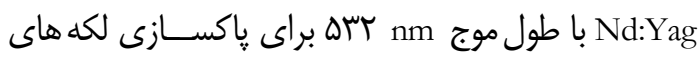

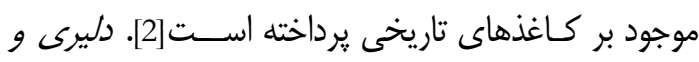
همكـارانش جهـت بررســـ لكـهـ هـا از روش هاى آناليز

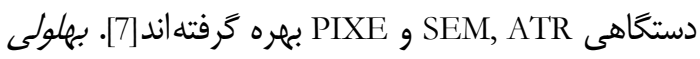

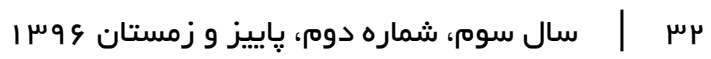


داريوش يبلنى، بهوسـيله تيغ بيستورى نمونه بردارى شد. مشخصات نمونهها در جدول الرائه شده است.
از اثر دسـت بر سـطح ·r نمونه از كاغذهاى تاريخى و

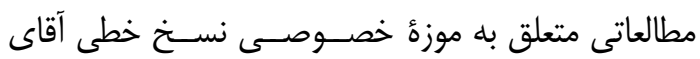

جدول ا: مشخصات نمونهها

Table 1: Samples Characteristics

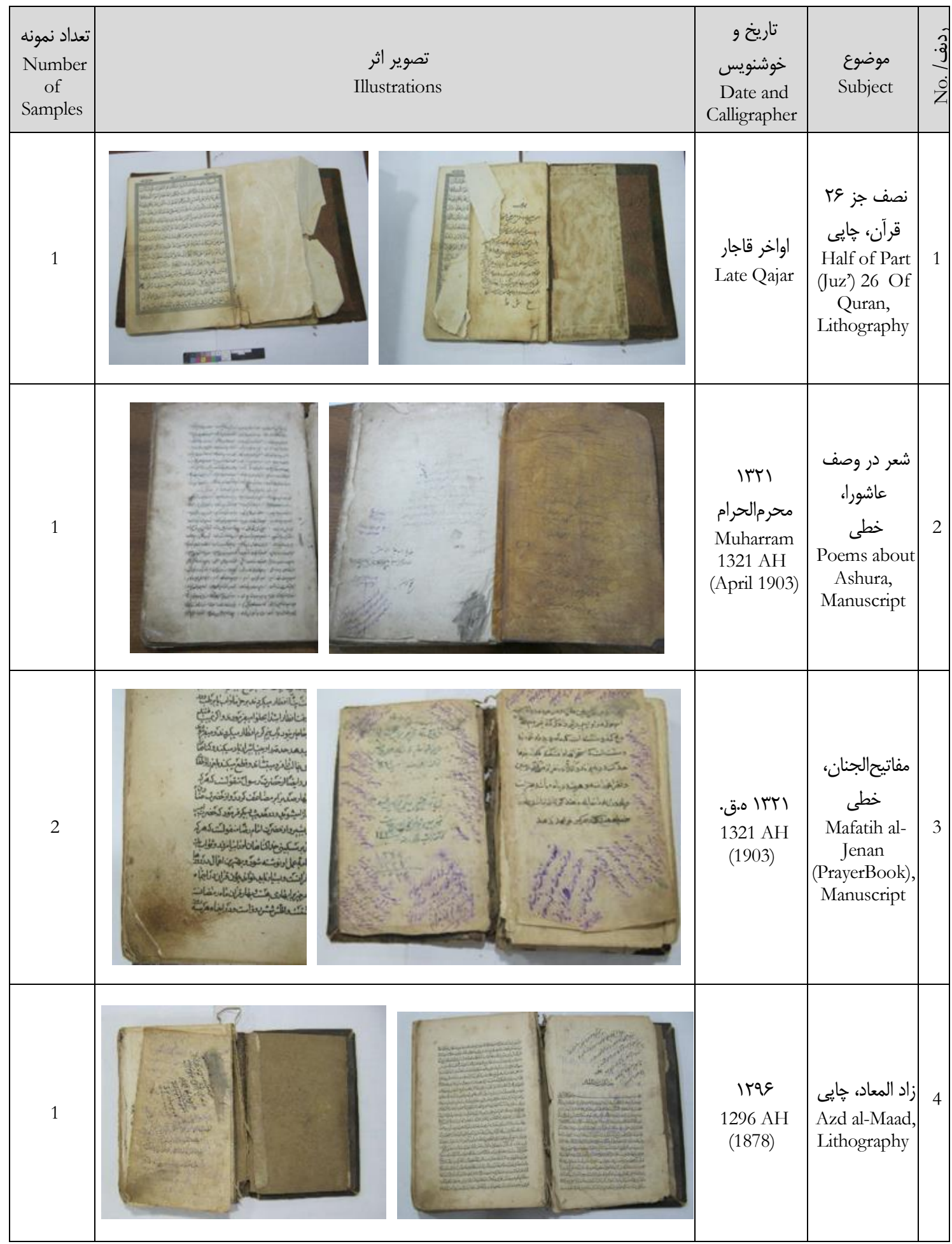




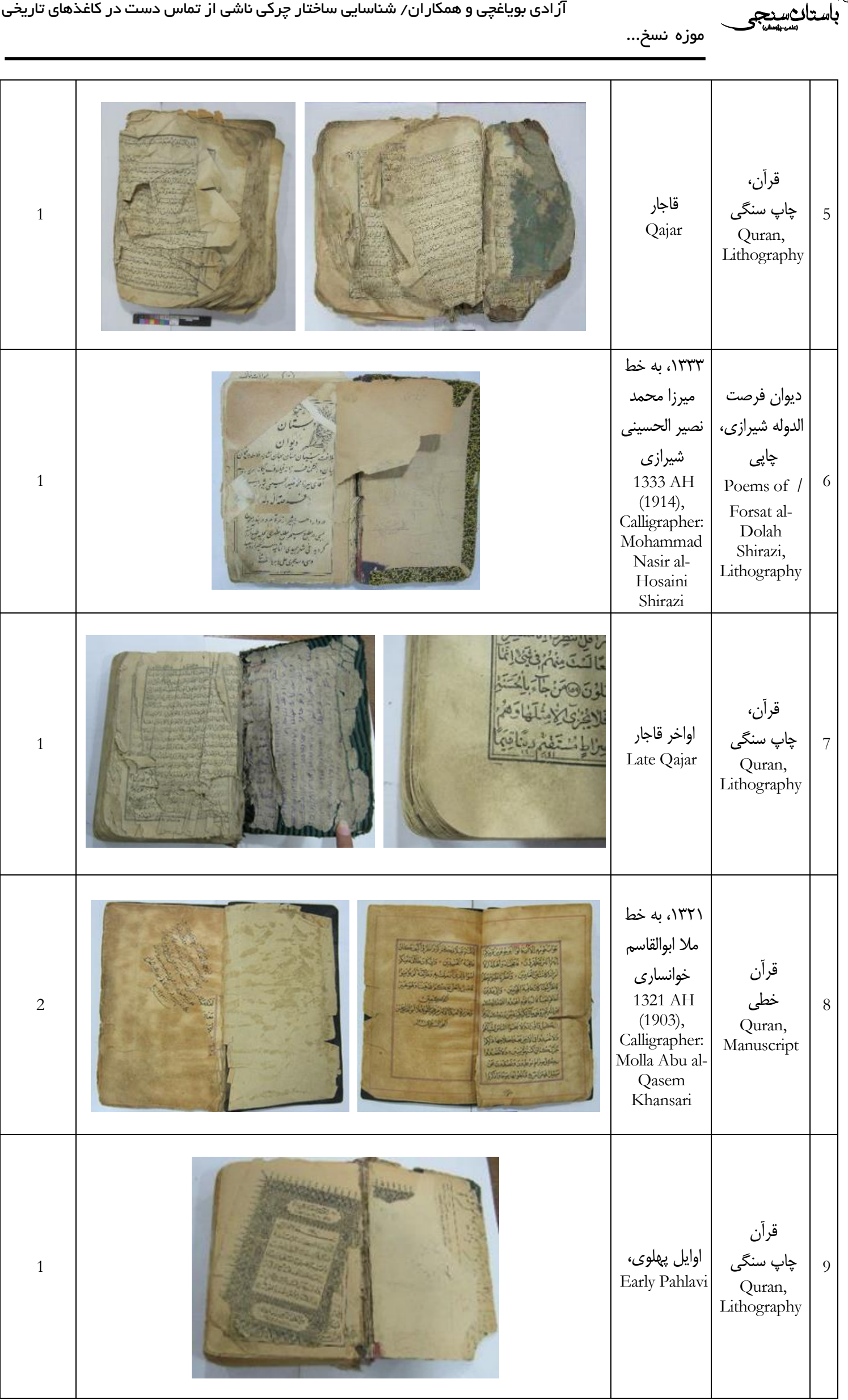


دو فصلنامه يزّوهه باستانسنجى

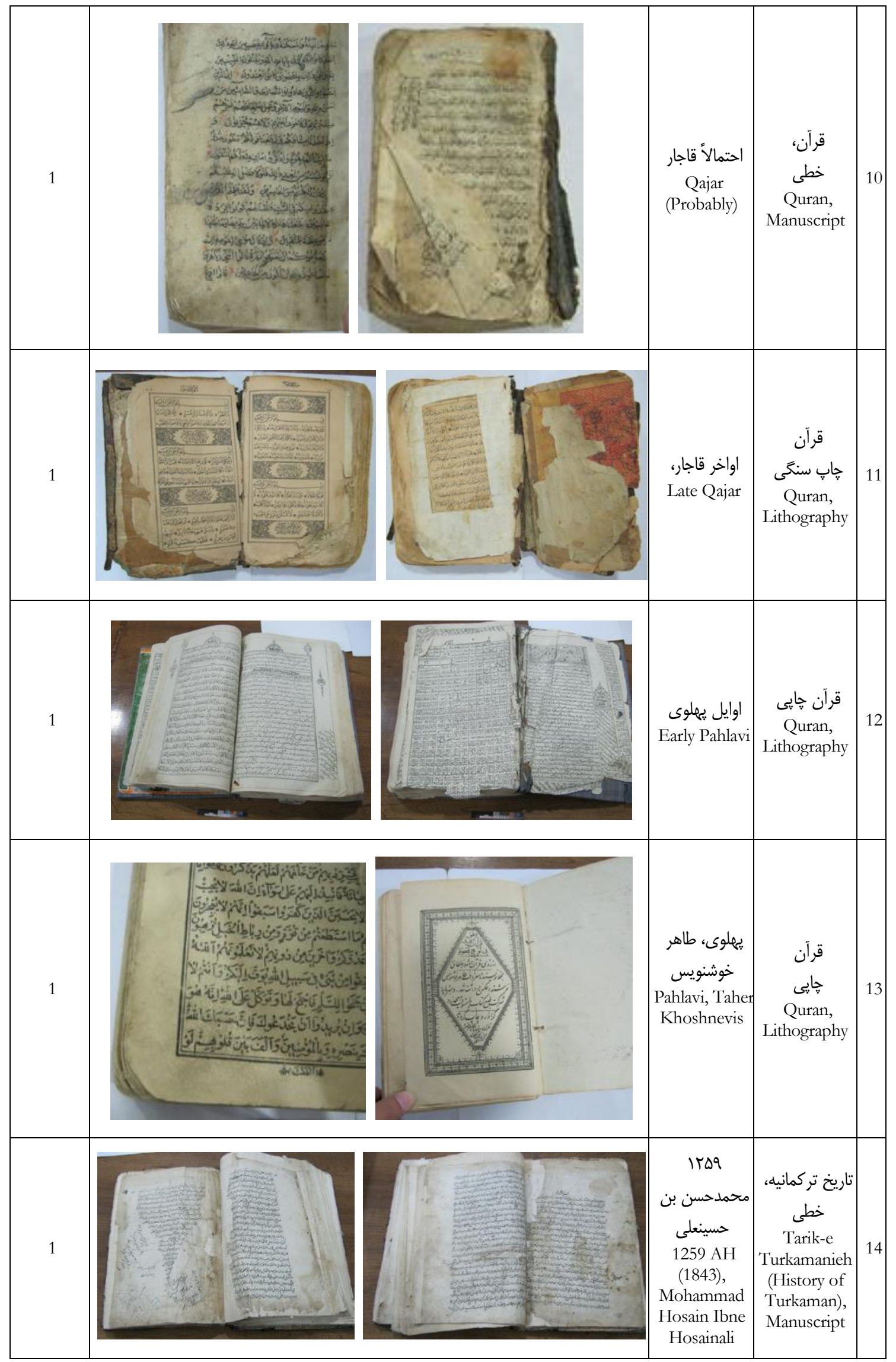

سال سوم، شماره دوم، ياييز و زمستان و وس ا هب 
تهيه شد تا در قياس با طيف لكه، تفاوتهاى ساختارى آن

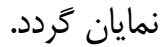

شـاسايى آهار نشاسته در جهت انتخاب نمونه ها و به

روش شـيمى كلاسـيك انجام شـــ. بدين ترتيب كه ابتدا

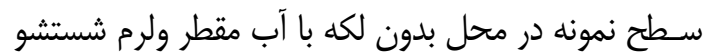

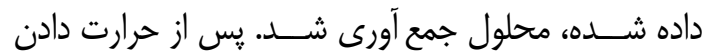

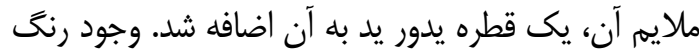

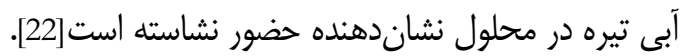

r. إم يافتهها و نتايج ץ-1. شـناسايى ساختار لكه ناشى از اثر دست روى كاغذهاى تاريخى

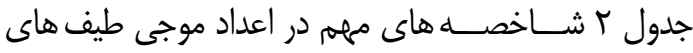

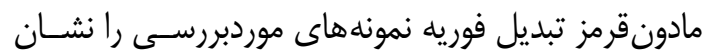

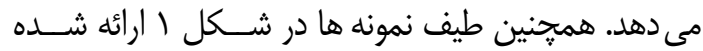
است. در طيف مادون قرمز تبديل فوريه نمونه هاى تاريخى نوار جذب در نواحى ناشسى از يبيوند C=O دانسـت كه عمدتاً در آميدهاى نوع cm اول و دوم در اين نواحى ديده مىشود. جذب در ناحئ

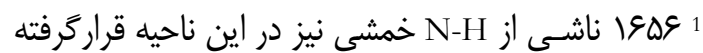
و با نوار جذب مذكور همبوشانى مى يابد. همجنين اين نوار را مى توان ناشى از C=C دانست اما وجود نوارهاى جذب مدابن قوى در مشـخصـات طيفى NH احتمال اختصاص آن به آنه

$$
\text { را C=O }
$$

جذب در

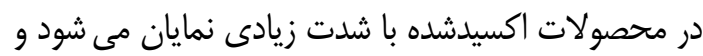
به دليل وجود جذب كو קكى در ناحيه شــده اسـت. اين نوع جذب ها در آميدها و آمين ها ديده

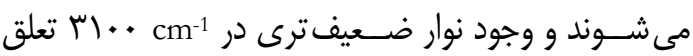
آنها به اين كروههاى عاملى را مىتواند قطعى سـازد. نوار

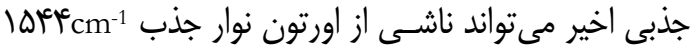

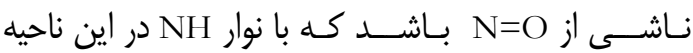

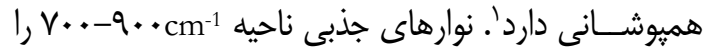
مى توان به N-H خمشى خارج از صفحهاى نسبت داد كه

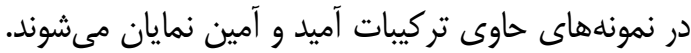

انتخاب اين نمونه ها به دلايل مختلفى صورت گَرفته

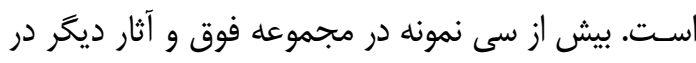

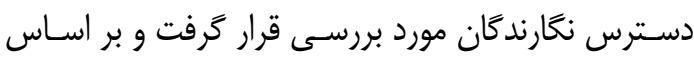
ميزان لكه موجود و امكان نمونهبردارى از آن و نيز يكسان

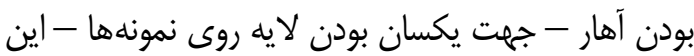
تعداد نمونه انتخاب و طيف مادون قرمز تبديل فوريه آن ها

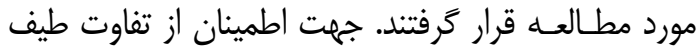
لكه با كاغذ، طيف كاغذ نمونهها نيز تهييه شد.

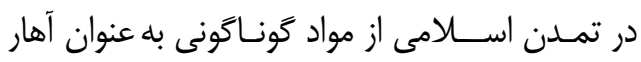
استفاده شده است[19]. هرجند صنعت كاغذسازى در ايران

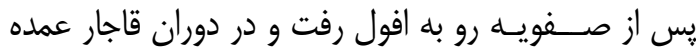
كاغذ مصـــفى در ايران از طريق واردات از كشــــورهاى

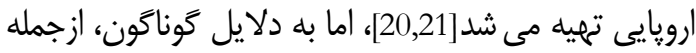

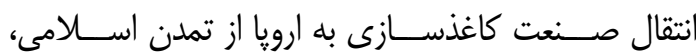

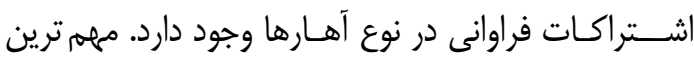
آهارى كه در تمدن اسلامى مورد استفاده قرار كَرفته و در ارويا نيز رايج بود نشاسته است. بر اين اساس و با توجه به به

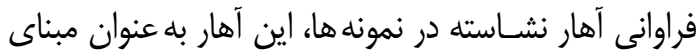

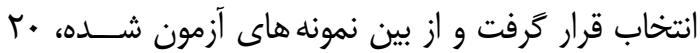
نمونه داراى آهار نشاسته انتخاب شدند.

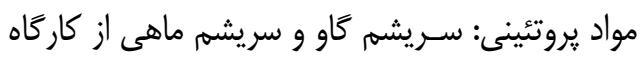
مرمت نقاشسى دانشـاه هنر اسلامى تبريز تهيه شد. ساير

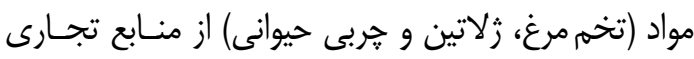
تهيه شد.

\section{r-r ابزار و روشها}

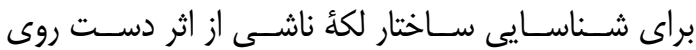
كاغذهاى تاريخى از طيفسـنجى مادونقرمز تبديل فوريه

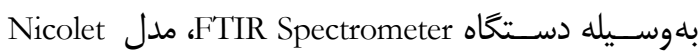
مexus 470 متصـل به نرمافزار OMNIC نسخه ا., \& استفاده شد. در

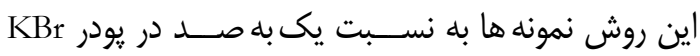

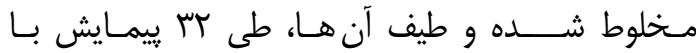
تفكيكيذيرى

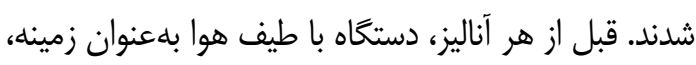

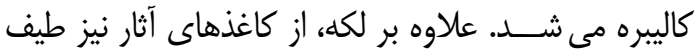


جدول r: اعداد موجى شاخص در طيف مادونقرمز تبديل فوريه نمونههاى بررسى شده؛ s: قوى، m: متوسط، w: ضعيف، b: كشيده، sh: شانه :bh: Table 2: Wavenumber Characteristics of FTIR spectra of samples; s: strong, m: medium, w: weak, b: broud, sh: shoulder

\begin{tabular}{|c|c|c|c|c|c|c|c|c|c|c|c|c|c|c|c|c|c|c|c|c|c|c|}
\hline \multirow{2}{*}{ تفسير Explanation/ } & \multicolumn{21}{|c|}{ نمونهها / Samples } & \multirow{2}{*}{ 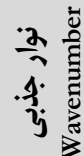 } \\
\hline & กิ & 2 & $\stackrel{\infty}{\sim}$ & $=$ & 눈 & 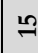 & I & $m$ & $\approx$ & $=$ & 운 & $a$ & $\propto$ & $\infty$ & $r$ & 6 & in & + & $n$ & $N$ & - & \\
\hline S-S & $\mathrm{m}$ & $\mathrm{m}$ & $\mathrm{m}$ & $\mathrm{m}$ & $\mathrm{s}$ & $\mathrm{m}$ & $\mathrm{m}$ & $\mathrm{m}$ & $\mathrm{w}$ & $\mathrm{m}$ & $\mathrm{m}$ & $\mathrm{m}$ & w & $\mathrm{v}$ & $\mathrm{w}$ & $\mathrm{m}$ & $\mathrm{s}$ & $\mathrm{w}$ & $\mathrm{m}$ & $\mathrm{m}$ & $\mathrm{m}$ & 早 \\
\hline S-S & $\mathrm{m}$ & $\mathrm{m}$ & $\mathrm{m}$ & $\mathrm{m}$ & $\mathrm{m}$ & $\mathrm{w}$ & $\mathrm{m}$ & $\mathrm{m}$ & $\mathrm{w}$ & $\mathrm{w}$ & $\mathrm{m}$ & $\mathrm{m}$ & w & & $\mathrm{w}$ & $\mathrm{m}$ & $\mathrm{m}$ & $\mathrm{m}$ & $\mathrm{m}$ & $\mathrm{m}$ & $\mathrm{m}$ & గి \\
\hline $\begin{array}{l}\text { Out of Page } \\
\text { Bending NH }\end{array}$ & $\mathrm{w}$ & $\mathrm{w}$ & $\mathrm{w}$ & & $\mathrm{w}$ & $\mathrm{w}$ & $\mathrm{m}$ & $\mathrm{m}$ & $\mathrm{w}$ & $\mathrm{w}$ & $\mathrm{w}$ & & w & & $\mathrm{w}$ & $\mathrm{m}$ & & $\mathrm{w}$ & & & & ర్రి \\
\hline $\begin{array}{l}\text { Out of Page } \\
\text { Bending NH }\end{array}$ & w & $\mathrm{w}$ & $\mathrm{w}$ & $\mathrm{w}$ & $\mathrm{w}$ & $\mathrm{w}$ & $\mathrm{m}$ & $\mathrm{w}$ & $\mathrm{w}$ & $\mathrm{w}$ & $\mathrm{w}$ & $\mathrm{w}$ & w & & $\mathrm{w}$ & $\mathrm{m}$ & $\mathrm{m}$ & & $\mathrm{w}$ & $\mathrm{m}$ & $\mathrm{m}$ & $\stackrel{10}{\infty}$ \\
\hline \multirow[t]{3}{*}{ Stretching C-N } & $\mathrm{s}$ & $\mathrm{s}$ & $\mathrm{s}$ & $\mathrm{s}$ & $\mathrm{s}$ & $\mathrm{s}$ & $\mathrm{s}$ & s & $\mathrm{m}$ & $\mathrm{s}$ & $\mathrm{m}$ & $\mathrm{m}$ & $\mathrm{m}$ & n & $\mathrm{m}$ & $\mathrm{s}$ & $\mathrm{s}$ & $\mathrm{m}$ & $\mathrm{s}$ & $\mathrm{s}$ & $\mathrm{s}$ & $\widetilde{\varrho}$ \\
\hline & & & & $\mathrm{w} / \mathrm{sh}$ & & $\mathrm{w}$ & & & & & $\mathrm{w} / \mathrm{sh}$ & & $\mathrm{m}$ & & $\mathrm{w}$ & sh & & $\mathrm{w}$ & & & & $\stackrel{\tilde{n}}{\varrho}$ \\
\hline & $\mathrm{w} / \mathrm{sh}$ & $\mathrm{w} / \mathrm{sh}$ & w/sh & $\mathrm{w} / \mathrm{sh}$ & $\mathrm{w} / \mathrm{sh}$ & w & $\mathrm{w}$ & $\mathrm{w}$ & $\mathrm{w}$ & & $\mathrm{m}$ & & $\mathrm{w}$ & & $\mathrm{m}$ & $\mathrm{w}$ & & $\mathrm{m}$ & & sh & sh & $\stackrel{\mathscr{Z}}{\Xi}$ \\
\hline $\begin{array}{l}\text { Stretching C-N } \\
\text { in C-N-C }\end{array}$ & & $\mathrm{w} / \mathrm{sh}$ & $\mathrm{w} / \mathrm{sh}$ & $\mathrm{w}$ & $\mathrm{w} / \mathrm{sh}$ & w & $\mathrm{m}$ & $\mathrm{w}$ & $\mathrm{w}$ & $\mathrm{w}$ & $\mathrm{w}$ & $\mathrm{w}$ & w & & $\mathrm{w}$ & $\mathrm{w}$ & & $\mathrm{m}$ & $\mathrm{w}$ & sh & sh & $\stackrel{8}{=}$ \\
\hline \multirow[t]{5}{*}{$\begin{array}{c}\text { Stretching C-N } \\
\text { in Amin I, II } \\
\end{array}$} & $\mathrm{w}$ & & & $\mathrm{w}$ & $\mathrm{w}$ & & & & & $\mathrm{w}$ & $\mathrm{w}$ & $\mathrm{w}$ & $\mathrm{m}$ & & $\mathrm{w}$ & $\mathrm{w}$ & $\mathrm{w}$ & & & & & สี \\
\hline & & $\mathrm{w}$ & & & & w & $\mathrm{w}$ & $\mathrm{w}$ & $\mathrm{w}$ & & & & & & & & & $\mathrm{m}$ & $\mathrm{w}$ & $\mathrm{w}$ & $\mathrm{w}$ & 导 \\
\hline & & $\mathrm{w}$ & $\mathrm{w}$ & $\mathrm{w}$ & $\mathrm{w}$ & $\mathrm{w}$ & $\mathrm{w}$ & $\mathrm{w}$ & $\mathrm{w}$ & $\mathrm{w}$ & $\mathrm{w}$ & & w & & $\mathrm{w}$ & $\mathrm{w}$ & & $\mathrm{w}$ & $\mathrm{w}$ & $\mathrm{w}$ & $\mathrm{w}$ & స్లి \\
\hline & $\mathrm{w}$ & & $\mathrm{w}$ & $\mathrm{w}$ & & w & & & $\mathrm{w}$ & $\mathrm{w}$ & $\mathrm{m}$ & $\mathrm{w}$ & $\mathrm{m}$ & n & $\mathrm{m}$ & $\mathrm{w}$ & $\mathrm{w}$ & $\mathrm{m}$ & & & & $\stackrel{2}{9}$ \\
\hline & & $\mathrm{w}$ & & & $\mathrm{w}$ & $\mathrm{m}$ & $\mathrm{w}$ & $\mathrm{w}$ & & & $\mathrm{w}$ & & & & & & & & & & & 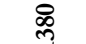 \\
\hline \multirow{2}{*}{$\begin{array}{c}\text { Asymmetric } \\
\text { Bending } \\
\text { Vibrations of } \\
\text { Alkanes }\end{array}$} & $\mathrm{m}$ & $\mathrm{m}$ & $\mathrm{m}$ & $\mathrm{m}$ & $\mathrm{s}$ & w & $\mathrm{m}$ & $\mathrm{w}$ & $\mathrm{w}$ & $\mathrm{m}$ & $\mathrm{m}$ & $\mathrm{w}$ & $\mathrm{m}$ & & $\mathrm{m}$ & $\mathrm{s}$ & $\mathrm{s}$ & $\mathrm{w}$ & $\mathrm{s}$ & $\mathrm{s}$ & $\mathrm{s}$ & 疋 \\
\hline & $\mathrm{m}$ & $\mathrm{m}$ & & & & w & $\mathrm{m}$ & $\mathrm{m}$ & $\mathrm{w}$ & $\mathrm{m}$ & & $\mathrm{w}$ & & & & & & & & & & $\stackrel{7}{1}$ \\
\hline Bending NH & $\mathrm{m}$ & $\mathrm{m}$ & $\mathrm{w}$ & $\mathrm{m}$ & $\mathrm{w}$ & $\mathrm{m}$ & $\mathrm{m}$ & $\mathrm{m}$ & $\mathrm{m}$ & $\mathrm{w}$ & $\mathrm{m}$ & w & w & & w & $\mathrm{m}$ & $\mathrm{w}$ & & $\mathrm{m}$ & $\mathrm{m}$ & $\mathrm{m}$ & $\stackrel{9}{\stackrel{9}{9}}$ \\
\hline Bending NH & & & & $\mathrm{w}$ & & & $\mathrm{w}$ & $\mathrm{w}$ & & $\mathrm{w}$ & & $\mathrm{w}$ & & & & & & & & $\mathrm{m}$ & $\mathrm{m}$ & $\begin{array}{l}\stackrel{10}{2} \\
\stackrel{2}{n}\end{array}$ \\
\hline $\begin{array}{c}\text { Stretching } \\
\mathrm{C}=\mathrm{O} / \\
\text { Bending } \mathrm{NH}_{2}\end{array}$ & $\mathrm{~s}$ & $\mathrm{~s}$ & $\mathrm{~m}$ & & $\mathrm{~s}$ & & & & $\mathrm{~m}$ & $\mathrm{~s}$ & & $\mathrm{~m}$ & $\mathrm{~m}$ & & $\mathrm{~m}$ & $\mathrm{~s}$ & $\mathrm{~s}$ & $\mathrm{~s}$ & & & $\mathrm{~m}$ & ?ơt \\
\hline \multirow[t]{2}{*}{$\begin{array}{l}\text { Stretching } \\
\quad \mathrm{C}=\mathrm{O}\end{array}$} & & & & $\mathrm{s}$ & & $\mathrm{s}$ & $\mathrm{s}$ & $\mathrm{m}$ & & & $\mathrm{s}$ & & & & & & & & $\mathrm{s}$ & $\mathrm{s}$ & & : \\
\hline & $\mathrm{w}$ & & $\mathrm{w}$ & $\mathrm{w}$ & $\mathrm{w}$ & w & $\mathrm{m}$ & $\mathrm{w}$ & $\mathrm{w}$ & $\mathrm{w}$ & $\mathrm{w}$ & $\mathrm{w}$ & $\mathrm{m}$ & n & $\mathrm{w}$ & $\mathrm{m}$ & $\mathrm{m}$ & $\mathrm{m}$ & sh & & & $\stackrel{9}{E}$ \\
\hline Amine Salts & $\mathrm{b} / \mathrm{w}$ & $\mathrm{b} / \mathrm{w}$ & $\mathrm{b} / \mathrm{w}$ & $\mathrm{b} / \mathrm{w}$ & $\mathrm{b} / \mathrm{w}$ & & $\mathrm{b} / \mathrm{w}$ & $\mathrm{b} / \mathrm{w}$ & $\mathrm{b} / \mathrm{w}$ & $\mathrm{b} / \mathrm{w}$ & $\mathrm{b} / \mathrm{w}$ & $\mathrm{b} / \mathrm{v}$ & $\mathrm{b} /$ & $\mathrm{w} \mid \mathrm{b}$ & $\mathrm{b} / \mathrm{w}$ & $\mathrm{b} / \mathrm{w}$ & $\mathrm{b} / \mathrm{w}$ & $\mathrm{b} / \mathrm{w}$ & $\mathrm{b} / \mathrm{w}$ & & & ఫ్రి \\
\hline Stretching S-H & $\mathrm{w}$ & $\mathrm{w}$ & $\mathrm{w}$ & $\mathrm{w}$ & $\mathrm{w}$ & & $\mathrm{w}$ & $\mathrm{w}$ & $\mathrm{w}$ & $\mathrm{w}$ & $\mathrm{w}$ & $\mathrm{w}$ & w & & $\mathrm{w}$ & $\mathrm{w}$ & w & & $\mathrm{w}$ & $\mathrm{w}$ & $\mathrm{w}$ & $\stackrel{\infty}{\stackrel{n}{n}}$ \\
\hline $\begin{array}{l}\text { Symmetric } \\
\text { Stretching CH }\end{array}$ & $\mathrm{m}$ & $\mathrm{w}$ & $\mathrm{w}$ & $\mathrm{m}$ & $\mathrm{w}$ & $\mathrm{m}$ & $\mathrm{s}$ & $\mathrm{s}$ & $\mathrm{w}$ & $\mathrm{m}$ & $\mathrm{m}$ & $\mathrm{m}$ & w & & $\mathrm{w}$ & $\mathrm{m}$ & $\mathrm{m}$ & $\mathrm{m}$ & $\mathrm{m}$ & $\mathrm{m}$ & $\mathrm{m}$ & 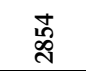 \\
\hline $\begin{array}{l}\text { Asymmetric } \\
\text { Stetching } \mathrm{CH}\end{array}$ & $\mathrm{s}$ & $\mathrm{m}$ & $\mathrm{m}$ & $\mathrm{m}$ & $\mathrm{m}$ & $\mathrm{m}$ & $\mathrm{s}$ & $\mathrm{s}$ & $\mathrm{m}$ & $\mathrm{s}$ & $\mathrm{m}$ & $\mathrm{m}$ & $\mathrm{m}$ & n & $\mathrm{m}$ & $\mathrm{s}$ & s & $\mathrm{s}$ & $\mathrm{s}$ & $\mathrm{s}$ & $\mathrm{s}$ & สิ \\
\hline $\begin{array}{l}\text { Asymmetric } \\
\text { Stretching in } \\
\text { Vinyl CH }\end{array}$ & sh & sh & sh & sh & sh & sh & sh & sh & & sh & sh & sh & sh & h & sh & sh & sh & sh & sh & sh & sh & ๙ั้ \\
\hline Stretching $\mathrm{OH}$ & s & $\mathrm{s}$ & $\mathrm{s}$ & $\mathrm{s}$ & $\mathrm{s}$ & s & $\mathrm{s}$ & $\mathrm{s}$ & $\mathrm{s}$ & $\mathrm{s}$ & s & $\mathrm{s}$ & $\mathrm{s}$ & ; & $\mathrm{s}$ & s & $\mathrm{s}$ & $\mathrm{s}$ & $\mathrm{s}$ & $\mathrm{s}$ & $\mathrm{s}$ & 㒵 竎 \\
\hline
\end{tabular}




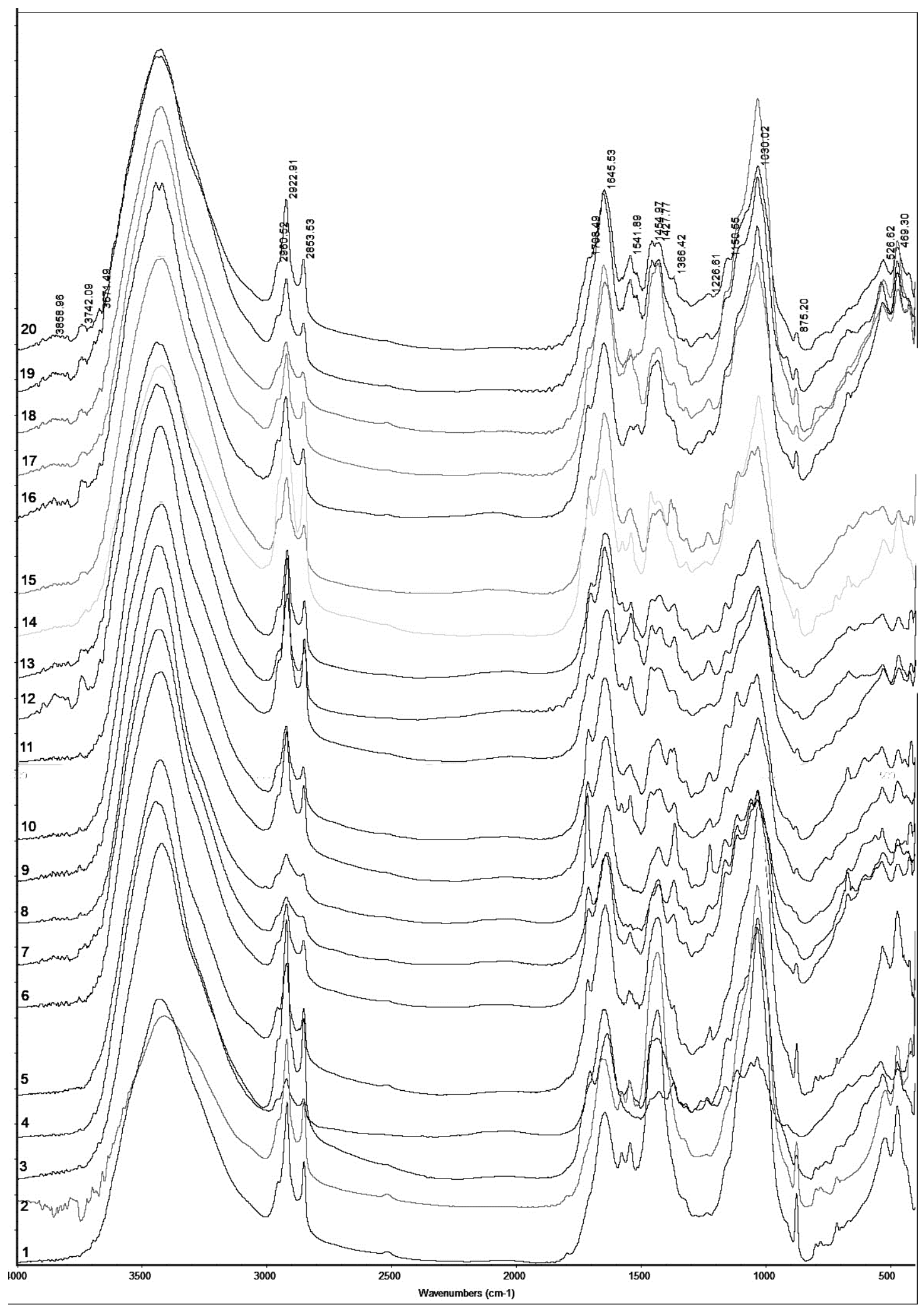

شكل (: طيف مادون قرمز تبديل فوريه نمونه هاى مورد مطالعه

Fig; 1: FTIR Spectra of samples

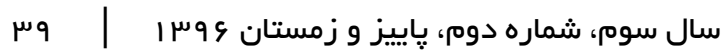




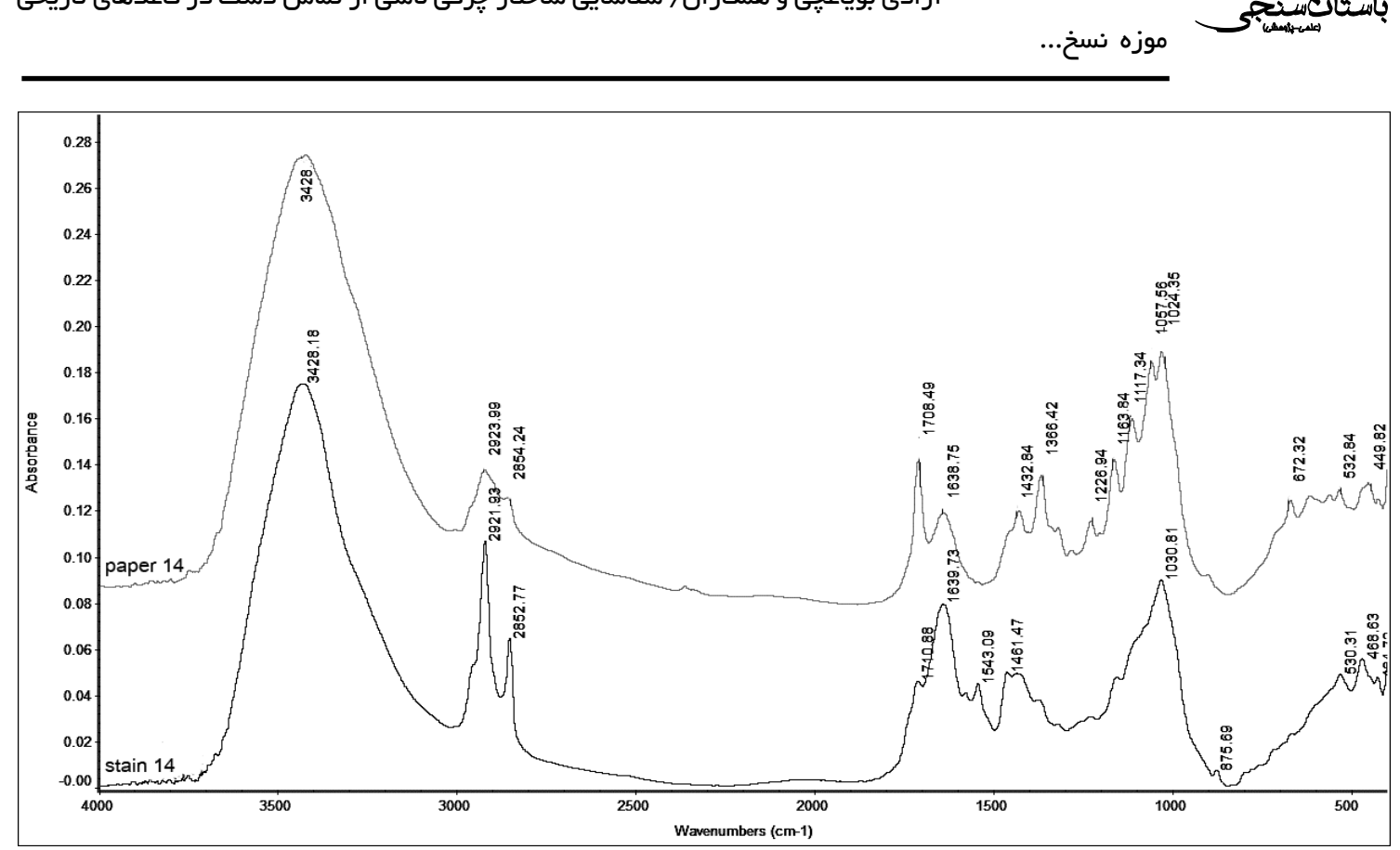

شكل r: طيف مادون قرمز تبديل فوريه كاغذ و لكه نمونه

Fig; 2: FTIR Spectra of Paper and Stain of Sample 14

دهان و به دليل تورق كتاب با انخشتان آلوده به بزاق ايجاد شده است.

بزاق دهان انسـان در حالت عادى ساختارى شبيه به آب دارد اما مصرف مواد غذايى مختلف و حالات و شرايط أنسان

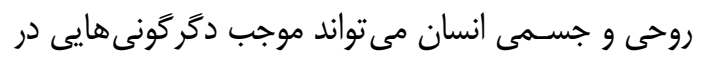

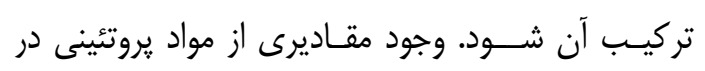

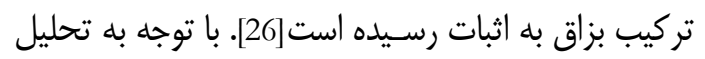

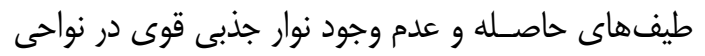
اختصـاصى كربونيل ناشى از C=O استرى كه شاخص

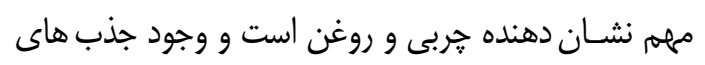

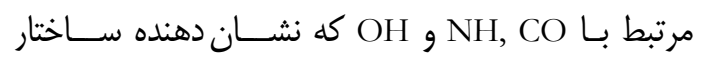

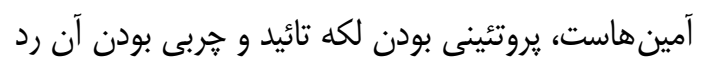
مى شود.

يروتئين هـاى غـــايى كَونه هاى مختلفى دارند. اما با

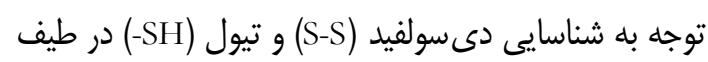

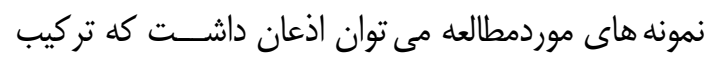

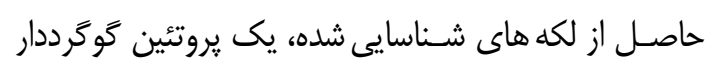

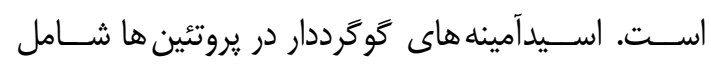

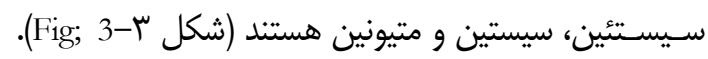

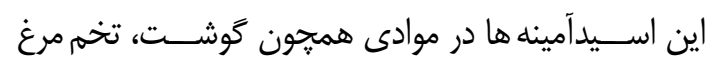
برخى حبوبات و غلات يافت مىشوند و از طريق ايجاد
نوارهاى

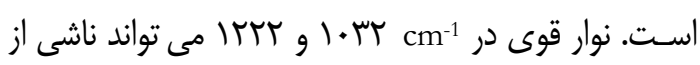

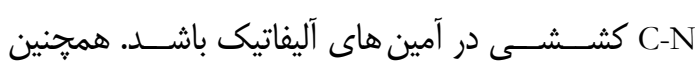

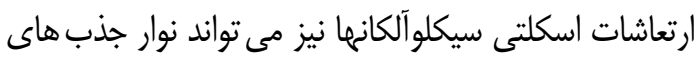
متوسـط تا قوى در ناحيه

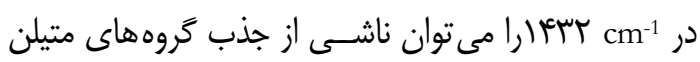

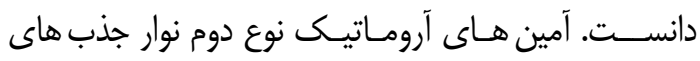
ضــيفى را مى توانند در ناحيه

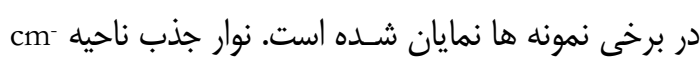

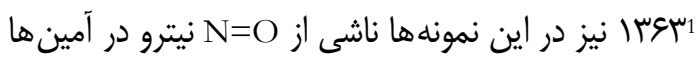

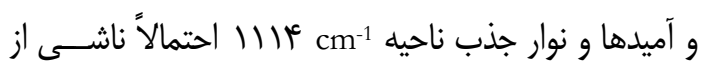
اســ[23,24]. طيف مادون قرمز تبديل فوريه لكه و

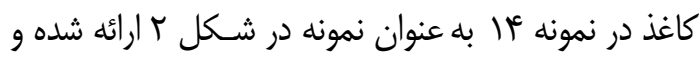

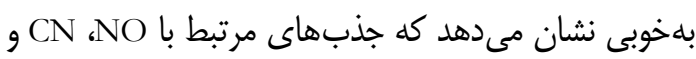
NH

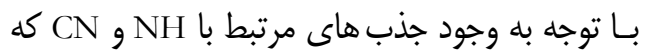

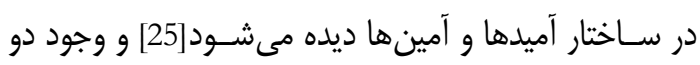
نوار جذب اختصاصى متعلق به تركيبات كو كرد (

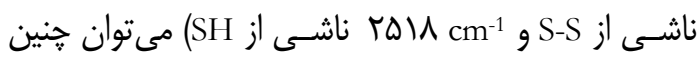

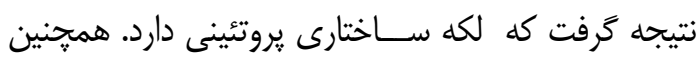

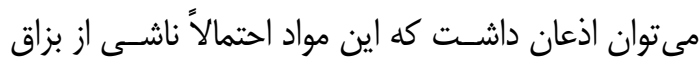

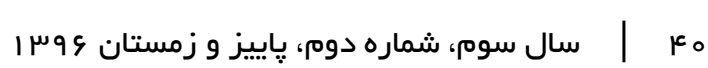


<smiles>N[C@@H](CS)C(=O)O</smiles>

Cysteine<smiles>N[C@H](CSSC[C@H](N)C(=O)O)C(=O)O</smiles>

Cystine<smiles>CSCCC(N)C(=O)O</smiles>

Methionine

شكل سّ: سه ساختار اسيدآمينه كَّرَ ددار [25]

Fig; 3: Three structure of sulfurid amino acids

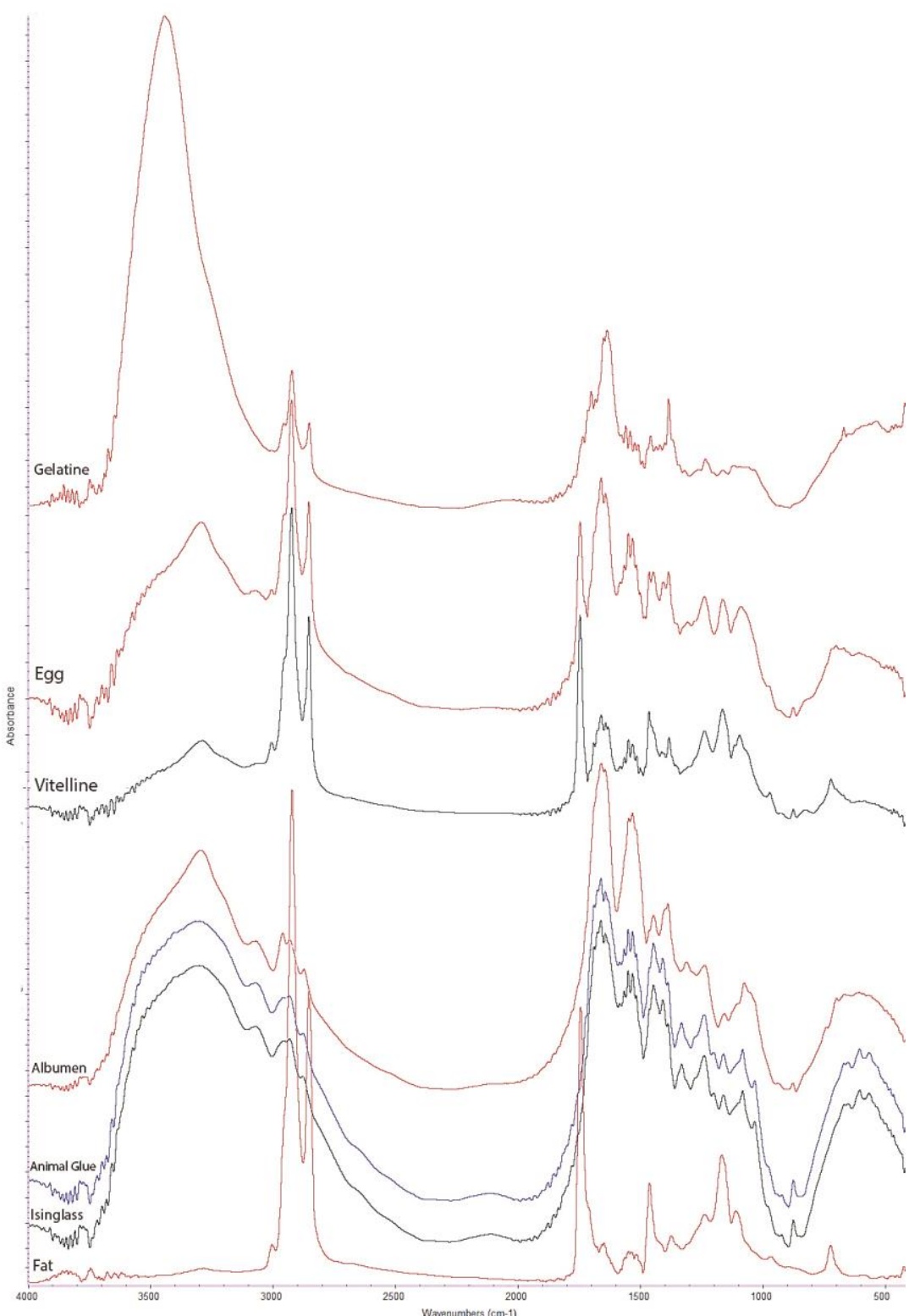

شكل ع: طيف مادون قرمز تبديل فوريه مواد تروتئينى و جربى حيوانى

Fig; 4: FTIR spectra of animal proteinous materials and fat

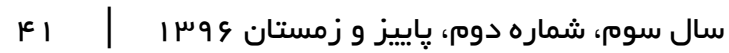




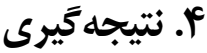

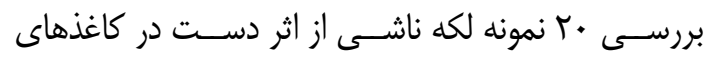

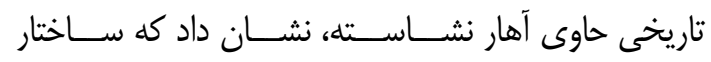
تشــكيل دهنده اين لكه ها شــامل تركيبات اســــــآمينه

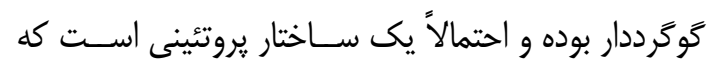

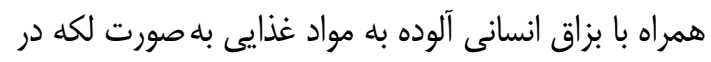

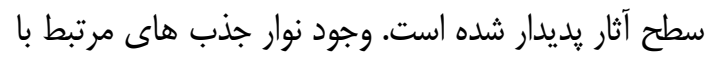

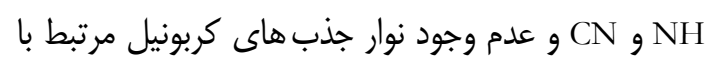

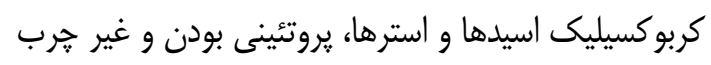

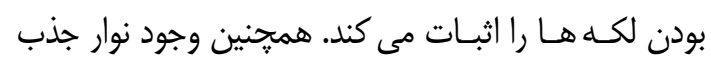

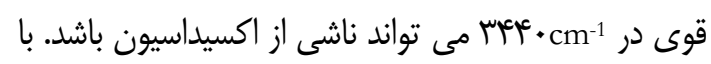

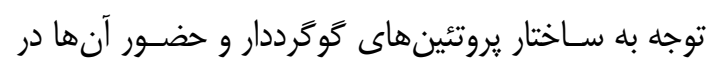

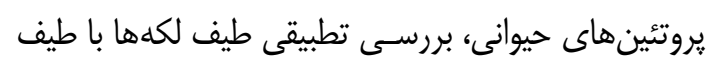

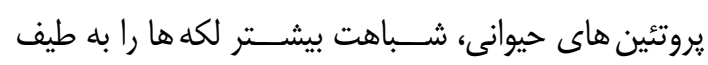

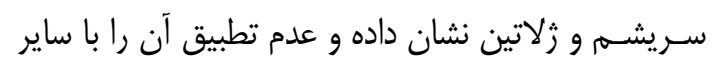

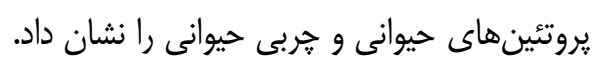

\section{سياسگزارى}

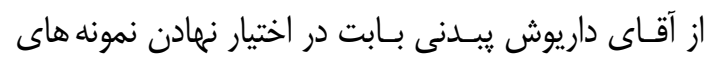

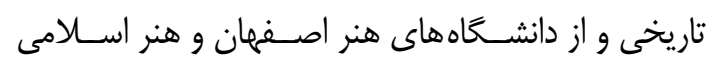
تبريز جهت همكارى در آناليز نمونهها قدردانى مىشئردان

\section{يـىنوشت}

ا. زمانى كه دو نوار جذبى در يك ناحيه همبوشـانى داشته

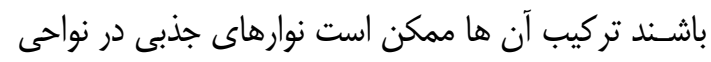

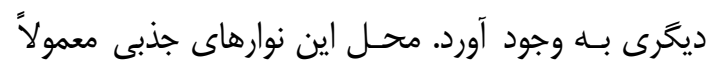

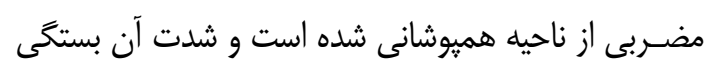

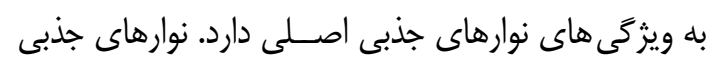

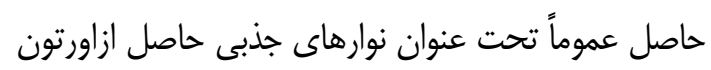

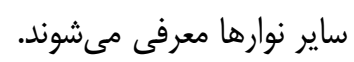

ييوندهاى يِيتيدى، يروتئين ها را مى سـازند[27]. با توجه به

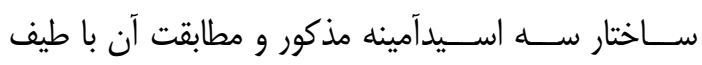
نمونه ها، קُندان نمى توان انتظار داشـتـ كه متيونين عامل اصلى حضور در خركى ها باشد. جراكه متيونين معمولاً در

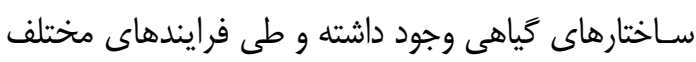
در بافت ســلولى، تبديل به ســاير تركيبات مى شـــود [28].

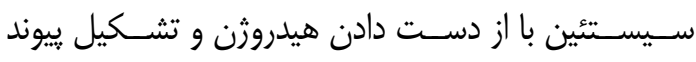

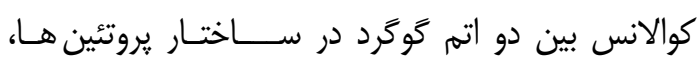

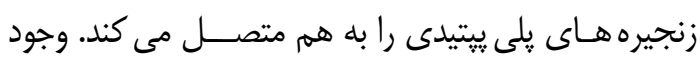

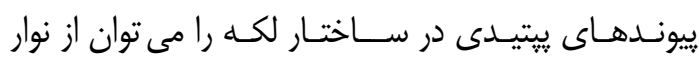

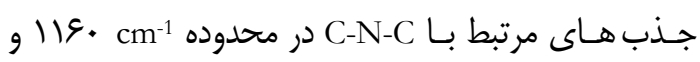

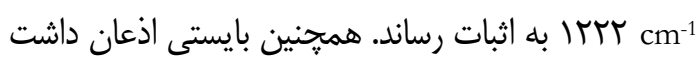

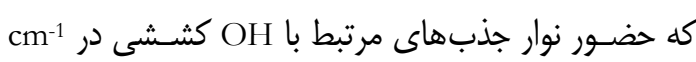

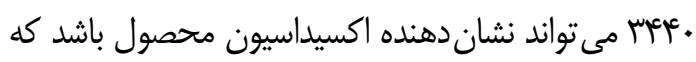
مى تواند علت مقاومت لكه ها در مقابل حلال هاى معاى معمول

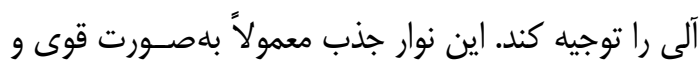

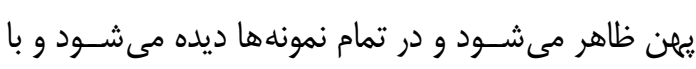

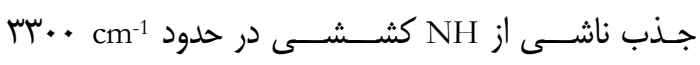

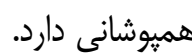

عمده آمينواسيدهاى گَوَّردار را بايستى در يروتئينهاى حيوانى جست. بلهويزه اينكه كلازن و كراتين

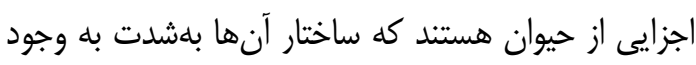

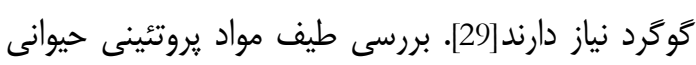

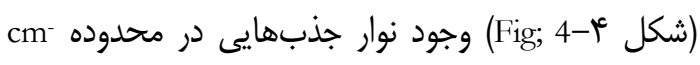

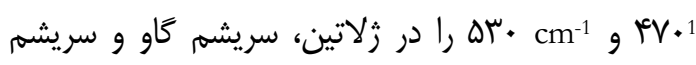

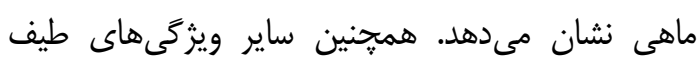

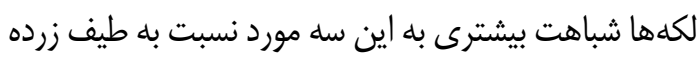

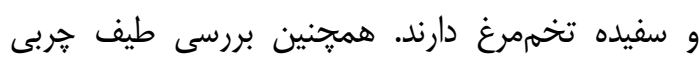

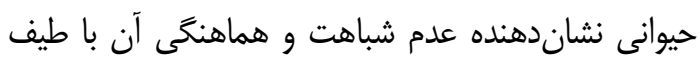

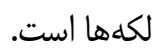

\section{References}

[1] Sadeqi Beyg A. Qanun al-sovar. In: Mayel Heravi N, editor. B. Decor. Islam. Civilization; Collect. rescripts Calligr. Ink Making, Pap. Making, Tazhib Cover. Mak., Mashhad: Islamic Research Institute of Astan Quds Razavi; 1993, p. 344-56. [in Persian]

$$
\begin{aligned}
& \text { صادقى بيك افشار. قانون الصور. در كتاب آرائى در تمدن }
\end{aligned}
$$

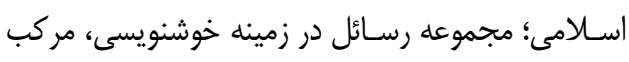

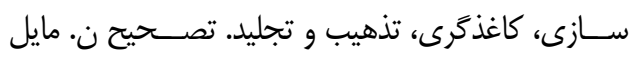

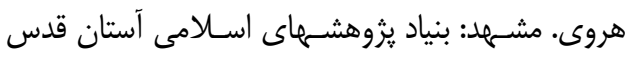

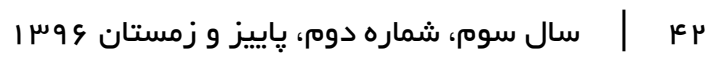




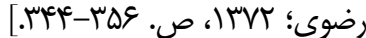

[2] Kaviani N. Application of $532 \mathrm{~nm}$ Nd: Yag laser in Cleaning of stains on Historical Papers. Art University of Isfahan, 2009. [in Persian] nm باويانى نوشين. كاربرد ليرز Nd:Yag

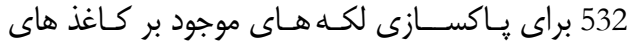

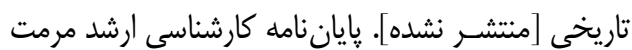

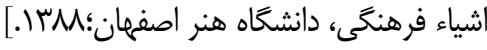

[3] Agrawal OP, Barkeshli M. Conservation of books, manuscripts and paper documents. INTACH; 1997.

[4] Stockman D. Treatment options for oil stains on paper. B Pap Gr Annu 2007;26:115-26.

[5] Plendeleith $\mathrm{H}$, Wener A. The consevation of antiquties and woks of at: treatment, repair and estoration. Tehran: 1971:101. [in Persian]

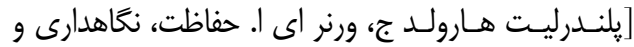

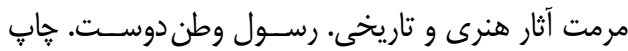

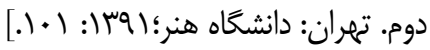

[6] Riederer J. Restaurieren+ Bewahren= Restoration and preservation. Tehran: Tehran Univercity; 1989. [in Persian]

[ريسدرر زوزف. روش هاى جديد مرمت و نتحهدارى اموال

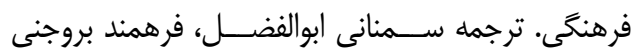

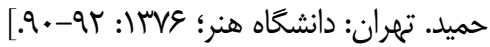

[7] Daliri H, Maleki MH, Malekian H. Application of Laser in Removing of Paper Stains. Restor Res 2009;6:46-59. [in Persian]

[دليرى حســن. ملكى محمد هادى. ملكيان حميد. كاربرد ليزر

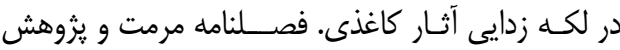

$[. \%$. $99.8: 1) \mathrm{M}$

[8] Bohlouli S, Ghodrati F. Stains and their Rmoval. Restor Res 2006;1:43-54. [in Persian]

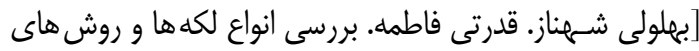

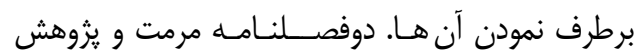

[.

[9] Bicchieri M, Ronconi S, Romano FP, Pappalardo L, Corsi M, Cristoforetti G, et al. Study of foxing stains on paper by chemical methods, infrared spectroscopy, micro-X-ray fluorescence spectrometry and laser induced breakdown spectroscopy. Spectrochim Acta Part B At Spectrosc 2002;57:1235-49. doi:https://doi.org/10.1016/S05848547(02)00056-3

[10] Choisy P, De La Chapelle A, Thomas D, Legoy MD. Non invasive techniques for the investigation of foxing stains on graphic art material. Restaurator 1997;18:131-52. doi:https://doi.org/10.1515/rest.1997.18.3.131

[11] Manso M, Pessanha S, Figueira F, Valadas S,
Guilherme A, Afonso M, et al. Characterisation of foxing stains in eighteenth to nineteenth century drawings using non-destructive techniques. Anal Bioanal Chem 2009;395:2029_ 36. doi: https://doi.org/10.1007/s00216-0093142-9

[12] Sarantopoulou E, Samardzija Z, Kobe S, Kollia $Z$, Cefalas AC. Removing foxing stains from old paper at $157 \mathrm{~nm}$. Appl Surf Sci 2003;208:311-6. doi: https://doi.org/10.1016/ S0169-4332(02)01379-X

[13] Ciofini D, Osticioli I, Micheli S, Montalbano L, Siano S. Laser removal of mold and foxing stains from paper artifacts: preliminary investigation. Fundam. Laser-Assisted Microand Nanotechnologies 2013, vol. 9065, International Society for Optics and Photonics; 2013, p. 906512.

[14] Blüher A, Grube A, Bornscheuer U, Banik G. A reappraisal of the enzyme lipase for removing drying-oil stains on paper. Pap Conserv 1997;21:37-47. doi: https://doi.org/ 10.1080/03094227.1997.9638597

[15] Nilghaz A, Zhang L, Shen W. Coffee stains on paper. Chem Eng Sci 2015;129:34-41. doi: https://doi.org/10.1016/j.ces.2015.02.017

[16] Szczepanowska H, Lovett CM. Fungal stains on paper-their removal and prevention. Stud Conserv 1988;33:13-4. doi: https://doi.org/ 10.1179/SIC.1988.33.S1.004

[17] Szcepanowska H, Mathia TG, Belin P. Morphology of fungal stains on paper characterized with multi-scale and multisensory surface metrology. Scanning 2014;36:76-85. doi: https://doi.org/10.1002/ sca. 21095

[18] Szczepanowska HM, Moomaw WR. Laser stain removal of fungus-induced stains from paper. J Am Inst Conserv 1994;33:25-32. doi: https://doi.org/10.1179/019713694806066437

[19] Barkeshli M. Historical and scientific analysis on sizing materials used in Iranian manuscripts and miniature paintings. Ayneye Miras 2006;4:30724. [in Persian]

$$
\begin{aligned}
& \text { بر كشـلى ماندانا. بررسى تاريخى و علمى روى آهارهاى } \\
& \text { مورد اسـتفاده در نســخ خطى و مينياتورهاى ايرانى. آينه }
\end{aligned}
$$

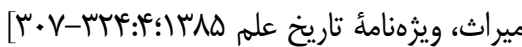

[20] Mohades M. A Few Lisence from Qajar Era. Tehran: Library, Museum and Document Center of Iran Parliament; 2001:101-3. [in Persian]

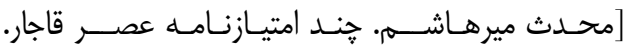

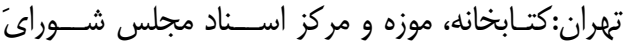

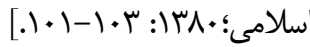

[21] Floor W. Traditional Crafts in Qajar Iran (18001925). Mazda; 2003:322. [in Persian] 
[فلور ويلم. صـــــايع كهن در دوره قـاجار. ترجمه بهارلو

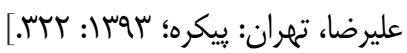

[22] Odegaard N, Carroll S, Zimmt WS. Material characterization tests for objects of art and archaeology. Archetype; 2000.

[23] Silverstein R, Bassler G, Morrill T. Spectroscopic identification of organic compounds. Esfahan: Esfahan univercity; 1981: 117-122. [in Persian]

] سـيلوراشـتين ر.م. وبسـتر ف.ايكس. شناسايى تركيبات

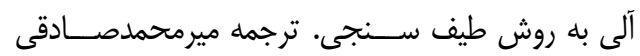

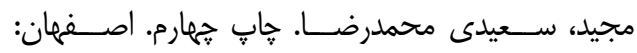

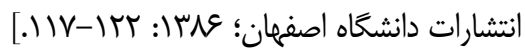

[24] Pavia D, Lampman G, Kriz G, Vyvyan J. Introduction to spectroscopy. Tehran: Learning; 2008:78-82. [in Persian]

] يـاويـا دونـالـــ لميمن گرى،كريز جرج، ويويـان، جيمز. نغرشـى بر طيف ســنجى. ترجمه موثق برهمن. تهران:

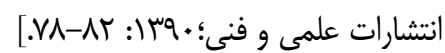

[25] Morrison R, Boyd R. Organic chemistry. Study guide to organic chemistry. Tehran: Allyn and Bacon; 1975. [in Persian]

[موريسـون تورنتون، نيلسـون بويد. شــيمى آلى. ترجمه

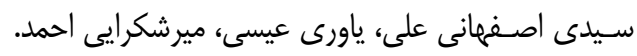

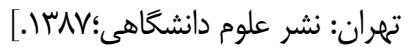

[26] Aghahosseini F, Dizgah E, Amirkhani S. Stimulated and unstimulated whole saliva compositions of dental female students Tehran University of Medical Sciences in 2005. J Islam Dent Assoc IRAN 2005;17:23-8. [in Persian] [آقاحسينى فرزانه، ميرزايى ديزگاه، اميرخانى سارا. تركيب

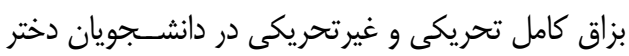

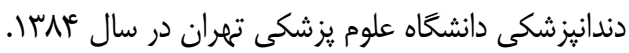

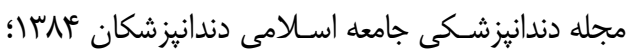

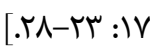

[27] Fatemi H. Chemisry of Food Materials. Tehran: Enteshar; 2012:64-6. [in Persian]

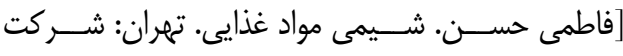

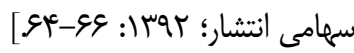

[28] Hell R. Molecular physiology of plant sulfur metabolism. Planta 1997;202:138-48. doi: https://doi.org/10.1007/s004250050112

[29] Mills J, White R. Organic chemistry of museum objects. New York: Routledge; 1987:85. [in Persian]

[ميلز ج. ا، وايـت ر. شــيمى آلى و آثار موزهاى. ترجمه

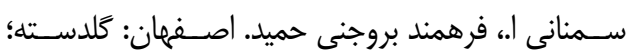

$[. \Lambda \Delta:$ : I بᄉ 